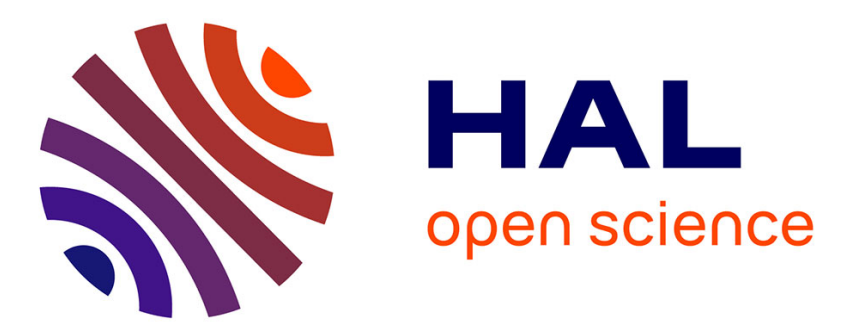

\title{
Experimental analysis of mixing ventilation efficiency using a vortex diffuser - comparison to a lobed multi-cone diffuser
}

\author{
Amina Meslem, Pierre Bragança, Kodjovi Sodjavi
}

\section{- To cite this version:}

Amina Meslem, Pierre Bragança, Kodjovi Sodjavi. Experimental analysis of mixing ventilation efficiency using a vortex diffuser - comparison to a lobed multi-cone diffuser. Science and Technology for the Built Environment, 2018, 24 (10), pp.1041-1053. 10.1080/23744731.2018.1490130 . hal-01915317

\section{HAL Id: hal-01915317 \\ https://hal-univ-rennes1.archives-ouvertes.fr/hal-01915317}

Submitted on 7 Nov 2018

HAL is a multi-disciplinary open access archive for the deposit and dissemination of scientific research documents, whether they are published or not. The documents may come from teaching and research institutions in France or abroad, or from public or private research centers.
L'archive ouverte pluridisciplinaire HAL, est destinée au dépôt et à la diffusion de documents scientifiques de niveau recherche, publiés ou non, émanant des établissements d'enseignement et de recherche français ou étrangers, des laboratoires publics ou privés. 


\title{
EXPERIMENTAL ANALYSIS OF MIXING VENTILATION \\ EFFICIENCY USING A VORTEX DIFFUSER - COMPARISON TO A LOBED MULTI-CONE DIFFUSER
}

\author{
Amina Meslem ${ }^{1, *}$, Pierre Bragança ${ }^{2}$, Kodjovi Sodjavi ${ }^{3}$ \\ ${ }^{1}$ LGCGM EA3913, University of Rennes, 3 rue du Clos Courtel, BP 90422, 35704 Rennes
} Cedex 7, France, "Corresponding author: amina.meslem@univ-rennes1.fr

${ }^{2}$ LaSIE, University of La Rochelle, Pôle Sciences et Technologie, avenue Michel Crépeau, 17042, La Rochelle, France

${ }^{3}$ Arts et Metiers ParisTech, DynFluid, 151 boulevard de l'Hôpital, 75013 Paris, France

\begin{abstract}
In a recent work, an innovative multi-cone diffuser integrating lobed inserts as vortices promoters was proposed, and was compared to its counterpart without lobed inserts. The former offers better mixing of the jet with the ambient air, and significantly improves thermal comfort.
\end{abstract}

In this study, the innovative diffuser is compared to a vortex diffuser under the same experimental conditions. The vortex diffuser is described in the scientific and technical 
literature as the best diffuser in terms of mixing efficiency due to the swirling effect, being thereby a reference for the innovative lobed diffuser.

The results demonstrate that the vortex diffuser does not produce the expected swirling effect. The rotation of the jet is prevented by the immediate attachment of the flow to the ceiling due to the Coanda effect. The jet behaves as a radial ceiling-attached flow having a poor mixing performance. It is believed that such a diffuser would be efficient when mounted on a long duct far away from the ceiling. Hence, it will be better suited for high ceilings, such as in industrial or commercial spaces. In this case, the proposed lobed diffuser becomes an appropriate and efficient mixing ventilation solution for rooms having low ceiling heights.

\section{KEYWORDS}

Mixing ventilation, lobed diffuser, vortex diffuser, cold jet, PIV measurements, thermal comfort

\section{PRACTICAL IMPLICATIONS}

Flow pattern and thermal comfort are analyzed in a room under mixing ventilation. Vortex (VD) and multi-cone lobed (LD) diffusers are compared in a cooling mode. The jet rotation vanishes near the VD exit due to the Coanda effect. It results in poor mixing performance for VD compare to LD. LD is best in terms of thermal comfort, pressure loss and noise generation.

\section{INTRODUCTION}

Mixing ventilation of residential spaces, particularly in the cooling mode, suffers from a bad reputation among users who often complain of draft problem, thermal discomfort and sometimes of high noise level generated by the fan and the air distribution circuit. Thermal discomfort and draft are mainly due to the fact that it is difficult to master the trajectory of a 
cold jet and to control its mixing with the ambient air. The way in which the air introduced into the room circulates and reaches the occupied zone of the room, depends strongly on the geometry of the diffuser and its position in the room. In mixing ventilation, there are usually dead pockets in the occupied zone difficult to reach by fresh and clean air. The user would try unsuccessfully to resolve this problem by increasing the jet volumetric flow rate, which in contrary would generate draught issues.

Hence, the ventilation efficiency should be homogenous in the occupied zone and high induction performance of the ventilation jet is a solution to achieve this goal. High induction allows the mitigation of stagnation regions given the optimal mix of the air jet with indoor air. As a result, the occupants would be more satisfied in terms of thermal comfort and air quality. The improvement of thermal comfort by using lobed inserts [1] was demonstrated in our previous work $[2,3]$, in cooling mode (radial jet generation) and heating mode (vertical jet generation), respectively. No additional energy cost and no noise level increase were observed. The concept of lobed inserts [1] consists in introducing vortices promoters in any type of commercial air diffuser without changes in its manufacturing process.

Contrary to the "built-in lobed diffuser", which we have considered previously $[4,5]$, this concept allows the manufacturer to adopt the innovation without complicated and high-priced changes in the factory production line of the diffuser. For the purpose of the present study, the inserts were made of resin material and were built using a 3D printer. In the context of the industrial integration of the innovation in the multi-cone diffuser, two couples of inserts, one for each mode (cooling and heating), should be series-produced in parallel to the production line, and marketed with the diffuser as accessories.

The assembly work needed to install the lobed inserts into the diffuser is not difficult and can be done by the user itself, when two times a year, in summer and in winter, respectively, he must hand in to set the diffuser in the suitable mode. 
The large-scale vortices generated by the lobed diffuser [6-8] improve mixing of the ventilation jet with the ambient air $[9,10]$. It results in better distribution of the heating or cooling loads, reducing local discomforts related to dead pockets and draftiness due to high air velocities and/or to large temperature gradients in the occupied zone.

The proposed concept of lobed inserts [1] could be considered as a competitor to the vortex diffuser widely marketed and recognized nowadays for its high mixing efficiency. In fact, the vortex diffuser is described in the scientific [11-13] and technical literature [14] related with mixing ventilation, as the best air diffuser in terms of mixing efficiency. The vortex diffuser produces a spiral rotating (or swirling) jet, enhancing mixing between the jet and the ambient air. The swirling effect is ensured by a special design of the fixed swirl impellers arranged at the diffuser outlet. The claimed high mixing efficiency of the vortex diffuser [11-14] makes it a reference for the proposed innovative lobed diffuser $[2,3]$. It is worth noting that the efficiency of the vortex diffuser in the context of mixing ventilation of buildings, is not supported by detailed experimental investigations. Previous experimental studies on the vortex diffuser [11, 12] are two decades old, and were based on pointwise, intrusive and omnidirectional velocity sensors. Many engineering applications involve swirling jets, such as in combustion chambers, jet engines, turbo machinery, mixing tanks, mixing ventilation. The majority of published studies dealing with swirling jets are dedicated to the mixing process in combustion chambers, where swirl helps to improve fuel/air mixture and stabilize the flame. The jet region of interest is limited to the vicinity of the diffuser outlet, and the results are obviously not extensible to the mixing ventilation application, due to the very different jet inlet conditions.

To our knowledge, there is no literature published to date on the behavior of the swirling jet in its far regions, which are so important in mixing ventilation. In addition, the influence of the potential increase in air induction using the vortex diffuser, on the flow behavior and the 
thermal comfort in the occupied zone is not discussed. In building ventilation application, previous experimental studies $[11,12]$ attempted to show in isothermal conditions, the higher efficiency of the vortex diffuser, relative to a multi-cone diffuser. Pointwise, intrusive and omnidirectional velocity sensors have been used along the trajectory of the ventilating jet, generated by a vortex diffuser and a reference multi-cone diffuser, respectively. Results analysis were based on the decreasing rate of maximum jet velocity ${ }^{\mathrm{Um}}{ }$, given by the velocity decay coefficient $\mathrm{K}_{\mathrm{v}}\left(\mathrm{U}_{\max } / \mathrm{U}_{\mathrm{n}}=\mathrm{K}_{\mathrm{v}}\left(\sqrt{\mathrm{A}_{\mathrm{n}}} / \mathrm{X}\right)\right.$, where $\mathrm{U}_{\mathrm{n}}$ and $\mathrm{A}_{\mathrm{n}}$ are jet inlet velocity and diffuser outlet area, respectively, and $\mathrm{X}$ is the axial distance from the diffuser outlet, which is directly related to the entrainment rate. The authors have found higher $\mathrm{K} v$ values for the vortex diffuser $(\sim 2.2)$ compared to the multi-cone diffuser $(\sim 1.9)$ and concluded that the jet produced by the vortex diffuser had a greater throw and therefore, a greater amount of ambient air was mixed with the jet .It seems that the very fact of a larger ${ }^{\mathrm{V}}{ }_{\mathrm{v}}$ coefficient for a vortex diffuser, compared to the multi-cone diffuser, is contrary to a well-accepted principle in the literature [15], which states that the higher the entrainment rate of jet, the smaller the coefficient ${ }^{K}{ }_{v}$.This amazing result of [11, 12] deserves a clarification.

In the literature related to fluid mechanics aspects of swirling jets, the strength of the swirl is gauged by the swirl number S [16], defined as the ratio of the axial flux of angular momentum to the axial flux of the axial momentum. Chigier and Chervinsky [17] established correlations between the velocity decay rate of the swirling jet, its axial spreading and its entrainment rate, and the swirl number S. It was particularly shown that in the first interval of $S$ ranging between 0 and 0.4, the increase in $\mathrm{S}$ lead to an increase in entrainment rate and a decrease in $\mathrm{K}_{v}$. Hence, the axial velocity component decreases faster, whereas the induced tangential and azimuthal velocity components increase. To put a link between swirling jets fundamental studies [16, 17] and studies on their application in mixing ventilation [11, 12], the use of 
omnidirectional anemometer to establish the law of axial jet velocity decay, as in $[11,12]$, obviously leads to an artefact: the measured velocity ( ${ }^{U_{\max }}$ ) is larger than in reality, which can lead to inconsistencies in flow analysis.

The experimental studies in references $[11,12]$ were cited or were used as a reference data in a number of numerical studies [18-20] dealing with CFD simulation of jets from ceiling vortex diffusers. The most recent numerical study [20] focuses on the effect of the angle between the impellers and the vertical axis, on the jet behavior and on the resulting air quality in the room (qualified by the predicted total age of the air [21, 22]). The numerical results show that when increasing the jet angle, the jet eventually attaches to the ceiling. The transition angle value, is between $50^{\circ}$ (vertical jet) and $55^{\circ}$ (radial jet). The radial jet configuration is better in terms of air quality in the room, but the increase in angle beyond $55^{\circ}$ decreases jet induction and air quality.

The present study is dedicated for the first time to a direct comparison under a cooling mode, of a multi-cone ceiling diffuser equipped with lobed inserts to a ceiling vortex diffuser. An experimental investigation is made on the airflow pattern and the thermal comfort generated in a full scale model room equipped with a heated manikin simulating an occupant. The climatic chamber is used to simulate summer mode under steady state thermal conditions. Having regard to the complexity of the swirling jet, velocity fields were acquired using 2D Particle Image Velocimetry (PIV), which gives two velocity components in the observed plane, without influence of the out-of-plane third component. As for thermal dissatisfaction and draft effect, the analysis is based on traditional pointwise measuring probes and the standards [23] and ASHRAE 55 [24].

\section{EXPERIMENTAL APPARATUS}




\subsection{Test chamber and diffusers}

A cubic laboratory chamber of an edge length of $3470 \mathrm{~mm}$ has been used for the experiments (Figure 1 a). A dropped ceiling was installed at height $2500 \mathrm{~mm}$ to simulate a standard room with low ceiling height. The temperature of the ambient air, $\mathrm{T}_{\mathrm{a}}$, measured at the extraction of the chamber, is controlled with a hydraulic circuit of capillary tubes inserted in the six walls, and connected to a heat pump. The air flow is conditioned with an air handling unit equipped with a fan, a heater and a chiller. The air flow is then brought to the chamber using an air diffusion circuit including at its extremity a plenum box followed by the diffuser. The diffuser centered on the ceiling is installed at the extremity of the plenum box. The plenum box includes a divergent, a short duct equipped with a perforated plate normal to the duct, a convergent, and again a short duct equipped with a honeycomb to ensure at the outlet of the terminal duct without diffuser, a top-hat mean velocity profile and a very weak turbulence intensity of $2 \%$ [2].

A simplified seated manikin (HM) of 8 heated parts and a total power of $81 \mathrm{~W}[2,25]$ was used to simulate an occupant located at the center of the room (Figure $1 \mathrm{~b}$ ). The manikin was designed to have a mean skin temperature of $32{ }^{\circ} \mathrm{C}$ in a room with ambient temperature at $26^{\circ} \mathrm{C}$ and with still air.

The initial flowrate, $\mathrm{Q}_{0}=200 \pm 6 \mathrm{~m}^{3} / \mathrm{h}$ and the initial jet temperature $\mathrm{T}_{0}$ (Table 1) are controlled with sensors placed between the air handling unit and the plenum box and again measured at the jet exit using a balometer from ACIN (Flowfinder mk2). The accuracy in flow rate measurement is $\pm 3 \%$ of the reading.

Figure 1 (c and d) shows the two air diffusers compared in this study under cooling conditions (Table 1). The first diffuser LD (Figure $1 \mathrm{c}$ ) is a multi-cone diffuser marketed by the ALDES company under the reference AF842 [26], in which we have introduced lobed inserts, to enhance the jet mixing with the ambient air. The reader will find in reference [2] the 
geometrical details of this diffuser and of the introduced lobed inserts. The advantage of the multi-cone diffuser with lobed inserts has been demonstrated in cooling mode with respect to its counterpart without inserts. The multi-cone lobed diffuser LD is compared in the present study to the ceiling vortex diffuser VD (Figure $1 \mathrm{~d}$ ), presently distributed by SCHAKO under the reference DHV - NW 160 [14]. About that special diffuser, the SCHAKO Company advances the commercial argument of the high induction of ambient air in the jet ensured by the special design of the fixed swirl impellers. The impellers have an inclination angle of $45^{\circ}$, hence, according to the numerical prediction of [20], the jet should be vertical.

The manufacturer's technical documentation specifies that the vortex diffuser DHV is designed especially for cooling and isothermal supply air pattern and is suitable to be flushmounted in ceiling up to $4 \mathrm{~m}$ high, without causing draft in the occupied zone. It is also specified that the supply air from the DHV diffuser enters the room horizontally and the increased induction allowed by the impellers causes the temperature difference and velocity to be rapidly reduced.

To verify the manufacturer's specifications of the ceiling swirl diffuser (Figure $1 \mathrm{~d}$ ), and to compare its efficiency to the one of the lobed multi-cone diffuser (Figure $1 \mathrm{c}$ ), the jet flow field (using 2D PIV, see the subsection §2.1) and the resulting thermal comfort in the occupied zone (Figure $1 \mathrm{a}, \mathrm{b}$ ) were characterized in cooling mode with a difference between the ambient air temperature $\left(\mathrm{T}_{\mathrm{a}}\right)$ and the jet temperature $\left(\mathrm{T}_{0}\right)$ of about $10{ }^{\circ} \mathrm{C}$ (see Table 1$)$. Thermal comfort analysis is based on the method of Fanger [27] proposed specially for nonuniform environments. A set of thermocouples (type K, accuracy of $\pm 0.3{ }^{\circ} \mathrm{C}$ ) and hot-sphere anemometers (TSI 8475, accuracy of $\pm 3 \%$ of the reading) was used for environmental parameters (air temperature and air speed) measurements. The sensors were placed on 16 vertical canes (Figure1 b). Each cane bears 4 sensors at the vertical positions specified in ASHRAE 55-2013 standard [24], i.e., $0.1 \mathrm{~m}, 0.6 \mathrm{~m}, 1.2 \mathrm{~m}$ and $1.8 \mathrm{~m}$ relatively to the room 
floor. These positions are those of ankles, waist, head of a seated occupant and head of a standing occupant, respectively [24, 27]. To cover the whole occupied zone, the 16 canes were installed in the chamber following the mesh given in (Figure1 b). Mean values $\left(\bar{T}_{\text {air }}\right.$ and $\overline{\mathrm{V}}_{\text {air }}$ ) of the 64 measurement points are given in Table 1.

Wall-surface temperature $\left(\mathrm{T}_{\mathrm{p}}\right)$ measurements were also performed. Each wall including the floor and the ceiling is divided into 4 subzones of equal dimensions. Each one is equipped with a thermocouple located in its center. Each wall surface has almost uniform temperature with a maximum difference of $1.7{ }^{\circ} \mathrm{C}$ between the 4 corresponding subzones. For the entire test chamber (i.e. 24 measurement points), the maximum difference is $3.3{ }^{\circ} \mathrm{C}$; the corresponding mean value $\bar{T}_{\mathrm{p}}$ is given in Table 1 . For mean radiant temperature $\left(\mathrm{T}_{\mathrm{mrt}}\right)$ calculation, the method described in [27] and in [28] based on wall-surface temperatures of the 6 surfaces and a seated manikin with unknown azimuthal angle is applied.

For each experiment, the steady-state conditions was achieved after a period of about $6 \mathrm{~h}$. After this period, environmental parameter measurements were carried out for a minimum duration of $8 \mathrm{~h}$ with a sampling time of $1 \mathrm{~min}$. The corresponding 480 samples are used to calculate statistical mean values given in Table 1. Personal parameters such as metabolic rate, mechanical work and clothing insulation, were fixed at $1.2 \mathrm{met}, 0 \mathrm{~W} / \mathrm{m}^{2}$ and 0.7 clo respectively, to evaluate the thermal comfort of a seated occupant, wearing a working clothing ensemble and having a sedentary activity. Calculations of thermal comfort indices were performed with a home-made software and the obtained PMV-PPD values were verified using the ASHRAE 55 Comfort tool [24, 29].

The pressure loss was measured according to standard [30] using a KIMO MP110 micromanometer. One pressure tap is installed at $1.5 \mathrm{D}$ (where $\mathrm{D}=160 \mathrm{~mm}$ is the diffuser neck-diameter) upstream the diffuser and the second in the occupied zone outside the jet flow. 
Sound pressure levels were measured with and without the diffusers using a handheld type 2250 Sound Level Meter of Class 1 Precision (tolerance of $\pm 0.7 \mathrm{~dB}$ ) from Bruel \& Kjaer. According to ISO 10052 [31], the diffuser should be considered as a technical equipment. Hence, the time average equivalent sound pressure level with A-weighting, Leq (dBA), must be measured with a recommended averaging time of $6 \mathrm{~s}$ [32]. Following standards specifications, Leq (dBA) was recorded at two locations in the chamber, P1 and P2 shown in Figure $1 \mathrm{a}$. These positions are corresponding [31] respectively to the nearest position to the diffuser located in the occupied zone, and the limit of the occupied zone in the case where people are seated.

\subsection{PIV measurements}

The airflows in indoor spaces of buildings are usually complex and difficult to characterize. Nowadays with current advanced laser and camera technologies, PIV technique becomes a powerful method getting more and more used to study room airflow distributions $[10,33,34]$. In fact, this method offers a high spatial resolution compared to traditional pointwise measurements techniques, making easier the analysis of large scale flows.

In the present study, the jet flow from the diffuser is characterized using a PIV measurement campaign conducted using a 2D2C Dantec Dynamics PIV system of $2 \mathrm{~Hz}$ acquisition rate. It is composed of a DantecHiSense $11 \mathrm{M}$ CCD camera with a sensor of $4000 \times 2672$ pixels, and a dual-cavity $2 \times 200 \mathrm{~mJ}$ laser. The airflow is seeded with Helium Filled Soap Bubbles (HFSB). Unlike the traditional aerosol-based tracer, this enables to increase the field size without peak locking effect [35].

The HFSB generation uses a commercial generator of Sage Action (model 5 - modified, Figure 2a) equipped with two injectors. The soap is produced by Sage Action (reference SAI 
1035 BFS). The flowrate of bubbles (initially 350 to 400 bubbles/s per injector and of adjustable size between 1.3 and $3.8 \mathrm{~mm}$ in diameter), along with their short life-duration was not sufficient to achieve an adequate spatial resolution of the PIV measurements.

To solve this problem, we designed an injector (Figure 2b, c) producing about $3000 \mathrm{bubbles} / \mathrm{s}$ of $1.5 \mathrm{~mm}$ in diameter. Two such designed injectors replaced the two injectors of Sage Action. Then, a PIV field of $1400 \times 1000 \mathrm{~mm}$ in size with a vector spacing of $11.3 \times 11.3 \mathrm{~mm}$ could be realized. A total of 3 PIV fields (Figure 3 a) were assembled to construct the whole field in the region of interest (i.e. the vertical half middle cross section of the room). For each PIV region, 500 pairs of images were acquired and processed through an adaptive multi-grid correlation algorithm handling the sub-pixel window displacement. The final size of the interrogation window was $64 \times 64$ pixels with an overlap of $50 \%$.

Beyond the global PIV fields obtained using HFSB (Figure $4 \mathrm{a}, \mathrm{b}$ ), the analysis of the wall jet generated by each diffuser requires a high spatial resolution. Hence, an aerosol-based PIV measurement campaign has also been conducted. In this case, the same PIV system is used along with olive oil droplets generated by a laskin generator. A total of 4 PIV windows of $374 \times 139 \mathrm{~mm}$ each with a vector spacing of $1.5 \times 1.5 \mathrm{~mm}$ were assembled to construct the ceiling jet field of $1274 \times 139 \mathrm{~mm}$ in size. For each PIV window, 1000 pairs of images were acquired and processed through an adaptive multi-grid correlation algorithm handling the subpixel window displacement. The final size of the interrogation window was $64 \times 64$ pixels and $32 \times 32$ pixels, respectively, with an overlap of $50 \%$.

The lobed multi-cone diffuser LD (Figure 1a) generates a conical ceiling attached jet. The flow is axisymmetric and therefore does not require any special precaution when vertical cross section is made. Conversely, the vortex diffuser equipped with impellers (Figure $1 \mathrm{~b}$ ) generates a discontinuous radial flow (Figure $3 \mathrm{~b}$ ) with a potential rotating effect around the Z-axis. If not well chosen, a vertical $2 \mathrm{D}$ view of the flow can lead to misinterpretations. 
Hence, before choosing vertical cross section of the jet coming from VD, horizontal crosssections at different heights $\mathrm{Z}$ ranging from $25 \mathrm{~mm}$ to $80 \mathrm{~mm}$ have been performed (Figure 4 c) using olive oil droplets-based PIV system. The fields are $708 \times 466 \mathrm{~mm}$ in size with a vector spacing of $5.7 \times 5.7 \mathrm{~mm}$. A number of 1000 pairs of images were acquired and processed following the same procedure as previously for the wall jet PIV fields. The resulting fields (Figure $4 \mathrm{c}$ ) show on the one hand, that there is no swirling effect around $\mathrm{Z}$, and indicate on the other hand, the persistence of a multi-jet behavior. Thus, a vertical section along one elementary jet (dashed line in Figure 3b) will be sufficient to describe the dynamics of the VD flow.

\section{RESULTS AND DISCUSSION}

\subsection{Air flow analysis}

Velocity distributions in the half-middle cross section of the room are given in Figure 4 for LD (Figure 4 a) and VD (Figure 4 b), respectively, which were obtained as explained above, by the assembly of three HFSB-based PIV fields (Figure 3 a). Some flow details are given in Figure 5 and are extracted from highly resolved fields issued from small scale aerosol-based PIV measurements [2]. In this figure the reference length, $\sqrt{A_{n}}$, used for axis normalization is the square root of the neck-area $\left(\mathrm{A}_{\mathrm{n}}=\pi \mathrm{D}^{2} / 4\right)$. The corresponding neck velocity $\mathrm{W}_{\mathrm{n}}=\mathrm{Q}_{0} / \mathrm{A}_{\mathrm{n}}$, is used as the reference velocity. The typical profile of the radial velocity component, U, of the wall jet, exhibits a maximum value, $\mathrm{U}_{\max }$, and the axial position $\mathrm{Z}$ where $\mathrm{U}=0.5 \times \mathrm{U}_{\max }$ is denoted $\mathrm{Z}_{0.5}$. 
As shown in our previous work [2], the jet from the LD it ceiling-attached and spreads radially till ceiling/wall corner. At the corner, the jet separates from the ceiling, impinges on the opposite wall, attaches to it, and spreads downwards as a vertical attached wall jet. It has been shown in [2] that the flow above the manikin has similar velocity profiles than those of a plume issued from a humanlike seated thermal manikin [36]. The jet from the vortex diffuser VD exhibits a similar behavior, but with higher velocities (Figure 5 a), a larger expansion (Figures $5 \mathrm{~b}$ ) and a suction zone that interacts with the thermal plume of the manikin.

On the decrease of the maximum velocity (Figure 5 a), the change of the curve slope at the distance $\mathrm{X} / \sqrt{\mathrm{A}_{\mathrm{n}}} \approx 5$ is the trace of the jet attachment to the ceiling, and the transition from free jet velocity profiles to wall jet velocity profiles (Figure 6). In fact, upstream $X=900 \mathrm{~mm}$ $\left(\mathrm{X} / \sqrt{\mathrm{A}_{\mathrm{n}}}=6.3\right)$ the jet is free; downstream this distance the jet becomes ceiling-attached. Beginning with $X=900 \mathrm{~mm}$, normalized velocity profiles are in a good agreement in the inner region $\mathrm{Z} / \mathrm{Z}_{0.5}<1$ (Figure 7) with similarity laws of two-dimensional wall-jets given in references $[37,38]$. The outer region $\left(\mathrm{Z} / \mathrm{Z}_{0.5}<1\right)$ bears the trace of impellers leading to velocity values lower than reference laws. Nevertheless, the data is getting closer to the reference laws as $\mathrm{X}$ increases, indicating that the imprint of inlet conditions has a tendency to disappear in the far field.

Regarding the comparison of $\mathrm{ED}$ and VD, recall that the initial conditions (Table 1) and the volumetric flowrate $\left(Q_{0}=200 \pm 6 \mathrm{~m}^{3} / \mathrm{h}\right)$ were the same for the two diffusers. The higher velocities observed in VD case are due to the multi-jet configuration (Figure $4 \mathrm{c}$ ) resulting from impellers imprint, which seems persistent since the jets do not merge over the observation distance $\mathrm{Z}=80 \mathrm{~mm}$. The vortex jet is here radial contrary to the numerical predictions in [20], where the simulated vortex jet would be vertical for impellers angle of $45^{\circ}$. Furthermore, the jet rotation seems to be stopped by the Coanda effect. 
To confirm our observations, an elementary jet is considered (Figure 8 a-b), from which tangential velocity component ( $\mathrm{V}$ in Figure $8 \mathrm{~b}$ ) and radial velocity component (U in Figure $8 b)$ are extracted. Figure 8 c gives a schematic of the vortex diffuser with expected flow trajectory in the horizontal plan due to impellers orientation. A zoom on the elementary jet field considered is provided in Figure 8 d. In Figure 8e, it is observed that near the diffuser outlet, the tangential component $\mathrm{V}$ reaches in absolute value $15 \%$ of the maximum velocity $\mathrm{U}_{\max }$ of the radial component $\mathrm{U}$ (Figure $8 \mathrm{f}$ ), but falls down and approaches zero very quickly. It could be observed in Figure $8 \mathrm{f}$, that the position of $\mathrm{U}_{\max }$ do not change anymore beginning with $\mathrm{X}=120 \mathrm{~mm}$. Thus, we confirm here that jet attachment to the ceiling (Figure $4 \mathrm{~b}$ ) clearly stopped the swirling effect claimed by the manufacturer [14]. It is worth noting that jet attachment to the ceiling was also observed in isothermal conditions with $\mathrm{Q}_{0}=200 \mathrm{~m}^{3} / \mathrm{h}$. This is not surprising since at high Reynolds number $\operatorname{Re}($ here $\operatorname{Re}=26000$, see Table 1 ) and low Archimedes number $\mathrm{Ar}$ (here $\mathrm{Ar}=0.006$ and $\mathrm{Ar}=0$, respectively), the jet near field is dominated by the inertia force. It is believed that at low volumetric flow rate and large temperature difference (i.e. low Re and high Ar), the jet would no longer be attached to the ceiling. In this case, the buoyancy force dominate the jet behavior and opposes the Coanda effect. Additional tests should be conducted to find the corresponding initial critical conditions.

Anyway, the result of the present study is the need for a revision (by the manufacturer) of the method of mounting the vortex diffuser so that the swirling effect can actually occur. In our opinion, it will be more suitable in mounting the vortex diffuser on a long duct far away from the ceiling, so that the Coanda effect would not occur. Hence, VD will be better suited for high ceilings, such as in industrial or commercial spaces. In this case, the multi-cone diffuser flush-mounted in the ceiling and equipped with lobed inserts [1] becomes an appropriate and efficient mixing ventilation solution for rooms having low ceiling height. The lobed inserts 
will be useful in this case to improve the thermal comfort in the occupied zone with respect to the same diffuser without inserts [2].

Additional small scale aerosol-based PIV measurements [2] were performed for the vortex diffuser in isothermal conditions at $\mathrm{Q}_{0}=200 \pm 6 \mathrm{~m}^{3} / \mathrm{h}$ (Figure 9), with the objective to compare (Figure 10) the corresponding velocity decay of VD to the literature $[11,12]$. The comparison reveals a very good agreement except near the jet exit for $X / \sqrt{A_{n}}<4$. In this region, our data falls between those of Chuah et al. [11] and Shakerin and Miller [12].

The $\mathrm{K}_{\mathrm{v}}$ - value of the VD is given in Table 2. In this Table, the $\mathrm{K}_{\mathrm{v}}$ - values previously obtained [2] for the conventional multi-cone diffuser without lobed inserts (CD) and with lobed inserts (LD), respectively, are included for comparison.

For the VD, the obtained $\mathrm{K}_{v_{\mathrm{v}}}-$ value $(\sim 1.9)$ is about $16 \%$ lower than the one $(\sim 2.2)$ obtained twenty years ago by Shakerin and Miller[12] by using omnidirectional anemometer. Taking into account that the $\mathrm{K}_{\mathrm{v}}$-value is extremely sensitive to the fitting region, the gap could be considered low. Furthermore, in the author's study the vortex diffuser was as in our case flush-mounted in the ceiling, which leads to say that the flow was probably attached and the swirling effect inhibited. Consequently, tangential and normal components vanished following the jet attachment, leading to a relatively good approximation of $U_{\max }$ by the omnidirectional sensor.

For the conventional multi-cone diffuser $(\mathrm{CD})$, the obtained value $(\sim 1.6)$ is about $19 \%$ lower than the one obtained by the authors [12]. The tendency for the two diffusers is the same, and differences are principally due to the different measurement techniques.

As for the lobed multi-cone diffuser (LD), its coefficient is $38 \%$ lower than that of our vortex diffuser (VD), due to higher mixing efficiency with the former. 
Despite the observations made above on the behavior of the jet issued from the vortex diffuser VD flush-mounted in the ceiling, which is not in line with expectations, we wanted to enrich the comparison of the two diffusers LD and VD, by addressing in the next section the issue of thermal comfort conditions generated in the occupied zone.

\subsection{Thermal comfort analysis}

The assessment of global thermal comfort is based on the PMV/PPD indices [27] considering a seated occupant, wearing a working clothing ensemble and having a sedentâry activity. The corresponding personal parameters are 1.2 met for metabolic rate, $0 \mathrm{~W} / \mathrm{m}^{2}$ for mechanical work and 0.7 clo for clothing insulation. The environmental parameters $\left(\mathrm{T}_{\text {air }}, \mathrm{V}_{\mathrm{air}}\right.$, RH and $\mathrm{T}_{\mathrm{mrt}}$ ) have been measured in the 64 nodes of the occupied zone (Figure $1 \mathrm{~b}$ ). Following the procedure described in [27] for non-uniform thermal environment, spatial distributions of the 64 nodes in terms of thermal comfort levels (A, B, C) provided in ISO 7730 standard [23] were considered (Figure 11) for VD and LD, respectively. The calculations of thermal comfort indices were performed with a home-made software and the obtained PMV-PPD values were verified using the ASHRAE 55 Comfort tool [29]. The corresponding statistic distributions and mean values are given in Table 3 and Table 4, respectively.

While on average (Table 3) the results indicate that the two diffusers generate similar levels of thermal comfort, with a slight advantage for the LD, this is not the case when the 64 nodes are statistically analyzed (Table 4). One can observe that all the 64 nodes fall into the category A for LD, compared to 77\% for VD (Table 4 and Figure 11). The VD case exhibits (Figure 11) higher air speeds (L) and lower air temperatures (T), leading to negative mean PMV-value (Table 3) corresponding to a slightly cold sensation. 


\subsection{Acoustic and pressure loss data analysis}

Figure 12 a1-a2, presents at positions P1 and P2 (Figure 1 b), global sound pressure levels as a function of the initial volumetric flow rate $\mathrm{Q}_{0}$. These global sound pressure levels reflect in the same time the possible noise generation of the diffuser and of the air handling unit and air distribution ducts. The air diffusion system is equipped with a plenum box, on which the diffuser is mounted. Two cases were considered: in the first one the measurements were performed without any diffuser mounted on the plenum, and the other case corresponds to the operation of the system with VD. The sound pressure levels of the VD itself were extracted (Figure 12b) and compared to the multi-cone diffusers (CD and LD) data from [2]. As recommended by ISO 10052 standard [31], mean values of pressure levels were calculated as representative values of global noise generated in the occupied zone. The mean value is an average weighted by the coefficients $2 / 3$ and $1 / 3$ of sound pressure levels in P1 and P2, respectively. Figure $12 \mathrm{c}$ shows the total pressure losses for VD, CD and LD, measured following EN 12238 standard [30], as a function of the inlet volumetric flow rate $\mathrm{Q}_{0}$.

The difference in pressure loss generation (Figure $12 \mathrm{c}$ ) between VD and LD increases with $\mathrm{Q}_{0}$. For $\mathrm{Q}_{0}=200 \mathrm{~m}^{3} / \mathrm{h}$, the pressure loss of $\mathrm{VD}(47 \mathrm{~Pa})$ is almost eight times higher than the one generated by LD (6 Pa). As for the sound pressure levels related to the diffuser noise generation (Figure $12 \mathrm{~b}$ ), a very important difference, from 7 to $10 \mathrm{dBA}$, is recorded with an advantage for $\mathrm{LD}$.

\section{CONCLUSIONS}

An innovative ceiling multi-cone diffuser equipped with lobed inserts (LD), which act as vortices promoters for the ventilation jet, has been confronted to a vortex diffuser (VD), which is specially manufactured for efficient mixing ventilation of buildings. The vortex 
diffuser is equipped with fixed swirl impellers arranged at the diffuser outlet to ensure flow rotation around the diffuser axis.

The study shows that the swirling effect vanishes rapidly near the diffuser exit due to the Coanda effect and the subsequent jet attachment to the ceiling. The jet behaves as a radial ceiling attached flow having a poor mixing performance.

Thermal comfort is less satisfactory for the vortex diffuser VD than in the case of the lobed multi-cone diffuser LD. For pressure drop and sound pressure level, VD is significantly less efficient than LD. For $\mathrm{Q}_{0}=200 \mathrm{~m}^{3} / \mathrm{h}$, the pressure loss of VD is almost eight times higher than the one generated by $\mathrm{LD}$, with a $7 \mathrm{dBA}$ increase in sound pressure level in the occupied zone.

Based on this study, it is believed that the VD will really generate a swirling jet if mounted on a long duct far away from the ceiling. Hence, it will be better suited for high ceilings, such as in industrial or commercial spaces. In this case, the proposed lobed diffuser LD becomes an appropriate and efficient mixing ventilation solution for rooms having low ceiling heights. 
Table 1: Experimental conditions

\begin{tabular}{|c|c|c|}
\hline Diffuser & LD_CJ & VD_CJ \\
\hline $\mathrm{T}_{0}\left({ }^{\circ} \mathrm{C}\right)$ & $13.4 \pm 0.2$ & $13.5 \pm 0.2$ \\
\hline $\mathrm{T}_{\mathrm{a}}\left({ }^{\circ} \mathrm{C}\right)$ & $23.8 \pm 0.4$ & $23.2 \pm 0.4$ \\
\hline $\mathrm{Re}=\mathrm{W}_{\mathrm{n}} \sqrt{\mathrm{A}_{\mathrm{n}}} / \mathrm{v}$ & 26000 & 26000 \\
\hline $\mathrm{Ar}=\mathrm{g} \sqrt{\mathrm{A}_{\mathrm{n}}} \Delta \mathrm{T} / \mathrm{T}_{\mathrm{a}} \mathrm{W}_{\mathrm{n}}^{2}$ & 0.0064 & 0.0059 \\
\hline $\mathrm{T}_{\mathrm{m} t \mathrm{t}}\left({ }^{\circ} \mathrm{C}\right)$ & $24.6 \pm 0.7$ & $24.0 \pm 0.7$ \\
\hline $\mathrm{T}_{\mathrm{p}}\left({ }^{\circ} \mathrm{C}\right)$ & $25.0 \pm 0.7$ & $24.3 \pm 0.7$ \\
\hline $\mathrm{T}_{\mathrm{op}}\left({ }^{\circ} \mathrm{C}\right)$ & $24.1 \pm 0.5$ & \\
\hline$\overline{\mathrm{T}}_{\text {air }}\left({ }^{\circ} \mathrm{C}\right)$ & $22.4 \pm 0.4$ & \\
\hline$\overline{\mathrm{V}}_{\text {air }}(\mathrm{m} / \mathrm{s})$ & $0.070 \pm 0.017$ & $0.091 \pm 0.023$ \\
\hline $\mathrm{V}_{\text {airmin }} / \mathrm{V}_{\text {airmax }}(\mathrm{m} / \mathrm{s})$ & $0.05 / 0.13$ & $0.02 / 0.27$ \\
\hline $\mathrm{RH}(\%)$ & $42 \pm 2$ & $42 \pm 2$ \\
\hline $\mathrm{Q}_{\mathrm{t}}\left(\mathrm{W} / \mathrm{m}^{2}\right)$ & 58.0 & 54.0 \\
\hline
\end{tabular}

LD_CJ: Lobed Diffuser_Cold Jet; VD_CJ:Vortex Diffuser_Cold Jet

Table 2: Comparison of $\mathrm{K}_{v}$ - values obtained in isothermal conditions

\begin{tabular}{c|ccc}
\hline Diffuser & Case & $\mathrm{K}_{v}$ & Fitting region \\
\hline \multirow{2}{*}{ Multi-cone } & CD IJ & 1.62 & $3<\mathrm{X} / \sqrt{\mathrm{A}_{\mathrm{n}}}<9$ \\
& & & $400<\mathrm{X}<1300$ \\
Multi-cone & LD IJ & 1.19 & $3<\mathrm{X} / \sqrt{\mathrm{A}_{\mathrm{n}}}<9$ \\
& & & $400<\mathrm{X}<1300$ \\
Vortex & VD IJ & 1.93 & $6.3<\mathrm{X} / \sqrt{\mathrm{A}_{\mathrm{n}}}<10.2$ \\
& & $900<\mathrm{X}<1450$ \\
\hline
\end{tabular}

IJ: isothermal jet - CD: conventional diffuser - LD: lobed diffuser 
Table 3: Mean values of PMV and PPD indices

\begin{tabular}{ccc}
\hline & LD & VD \\
\hline PMV & 0.08 & -0.19 \\
PPD $(\%)$ & 5.2 & 5.8 \\
\hline
\end{tabular}

Table 4: Statistic distribution of PPD index for the two diffusers

\begin{tabular}{cccc}
\hline Cat. ISO 7730 & Conditions & LD & VD \\
\hline $\mathrm{A}$ & $\mathrm{PPD}<6 \%$ & 100 & 77 \\
\hline $\mathrm{B}$ & $6<\mathrm{PPD}<10 \%$ & 0 & 23 \\
\hline $\mathrm{C}$ & $10<\mathrm{PPD}<15 \%$ & 0 & 0 \\
\hline Out & $\mathrm{PPD}>15 \%$ & 0 \\
\hline
\end{tabular}




\section{REFERENCES}

1. Vialle, P.J., E. Leroy, and A. Meslem, Diffusion device with lobe inserts and fan coil comprising such a device, in European Patent Office. 2015.

2. Bragança, P., et al., Airflow characteristics and thermal comfort generated by a multicone ceiling diffuser with and without inserted lobes. Building and Environment, 2016. 108: p. 143-158.

3. Bragança, P., et al., Passive control strategy for mixing ventilation in heating mode using lobed inserts. Energy and Buildings, 2016. 133: p. 512-528.

4. Meslem, A., I. Nastase, and F. Allard, Passive mixing control for innovative air diffusion terminal devices for buildings. Building and Environment, 2010. 45: p. 26792688.

5. Nastase, I., et al., Lobed grilles for high mixing ventilation - An experimental analysis in a full scale model room. Building and Environment, 2011. 46(3): p. 547-555.

6. Nastase, I., A. Meslem, and P. Gervais, Primary and secondary vortical structures contribution in the entrainement of low Reynolds number jet flows. Experiments in Fluids, 2008. 44(6): p. 1027-1033.

7. Meslem, A., M. El-Hassan, and I. Nastase, Analysis of jet entrainment mechanism in the transitional regime by time-resolved PIV. Journal of Visualization, 2011. 14(1): p. 41-52.

8. Nastase, I. and A. Meslem, Vortex dynamics and mass entrainment in turbulent lobed jets with and without lobe deflection angles. Experiments in Fluids, 2010. 48(4): p. 693-714.

9. Meslem, A., et al., A comparison of three turbulence models for the prediction of parallel lobed jets in perforated panel optimization. Building and Environment, 2011. 46: p. 2203-2219.

10. Cao, G., et al., A review of the performance of different ventilation and airflow distribution systems in buildings. Building and Environment, 2014. 73: p. 171-186.

11. Chuah, Y.K., S.C. Hu, and J.M. Barber, Airflow Characteristics of Circular Ceiling Diffusers. International Journal on Architectural Science, 2000. 1: p. 59-67.

12. Shakerin, S. and P.L. Miller. Experimental study of Vortex Diffusers. in 1996 Annual Conference. 1996. San Antonio, TX.

13. Awbi, H.B., Ventilation of Buildings. Second edition ed. 2003, London, U.K.: SPON. 522.

14. SCHAKO. Swirl diffuser DHV - Technical documentation. Available from: https://schako.com/wp-content/uploads/dhv_en.pdf.

15. ASHRAE, Space air diffusion, in ASHRAE Handbook: Fundamentals, ASHRAE, Editor. 2009.

16. Gupta, A.K., D.G. Lilley, and N. Syred, Swirl flows. 1984: Abacus Press.

17. Chigier, N.A. and A. Chervinsky, Experimental Investigation of Swirling Vortex Motion in Jets. Journal of Applied Mechanics, 1967. 34(2): p. 443-451.

18. Aziz, M.A., et al., Experimental and Numerical Study of A/C Outletsand Its Impact on Room Airflow Characteristics. World Academy of Science, Engineering and Technology, 2012. 6: p. 387-396.

19. Sajadi, B., M.H. Saidi, and A. Mohebbian, Numerical investigation of the swirling air diffuser: Parametric study and optimization. Energy and Buildings, 2011. 43(6): p. 1329-1333.

20. Tavakoli, E. and R. Hosseini, Large eddy simulation of turbulent flow and mass transfer in far-field of swirl diffusers. Energy and Buildings, 2013. 59: p. 194-202. 
21. Li, X., et al., Total air age: an extension of the air age concept. Building and Environment, 2003. 38(11): p. 1263-1269.

22. Gan, G., Effective depth of fresh air distribution in rooms with single-sided natural ventilation. Energy and Buildings, 2000. 31(1): p. 65-73.

23. ISO, Ergonomics of the thermal environment -- Analytical determination and interpretation of thermal comfort using calculation of the PMV and PPD indices and local thermal comfort criteria, in ISO 7730. 2005.

24. ANSI/ASHRAE, Thermal environmental conditions for human occupancy, in Standard 55-2013. 2013.

25. Dogeanu, A., et al., Conception of a simplified seated thermal manikin for CFD validation purposes. Romanian Journal of Civil Engineering, 2014. 5.

26. ALDES. Documentation technique diffuseur série AF/AT 842. Available from: https://pro.aldes.fr/produits/serie-af-842-aluminium-p27819.htm.

27. Fanger, P.O., Thermal Comfort, Analysis and Applications in Environmental Engineering. 1970: Mc Graw Hill Book Company.

28. ISO, Ergonomics of the thermal environment -- Instruments for measuring physical quantities, in ISO 7726. 1998.

29. ASHRAE. Thermal comfort tool. 2011; Available from: https://www.ashrae.org/resources--publications/bookstore/thermal-comfort-tool.

30. AFNOR, Ventilation des bâtiments - Bouches d'air - Essais aérodynamiques et caractérisation pour applications en diffusion à mélange, in NF EN 12238. 2001.

31. ISO, Acoustique -- Mesurages in situ de l'isolement aux bruits aériens et de la transmission des bruits de choc ainsi que du bruit des équipements -- Méthode de contrôle, in ISO 10052. 2004.

32. Ministère de l'Écologie du Développement durable et de l'Énergie Ministère du Logement et de l'Égalité des territoires, Guide de Mesures Acoustiques. 2014.

33. G. Cao, M.S., J. Kurnitski, M. Ruponen, O. Seppanen, Particle image velocimetry (PIV) application in the measurement of indoor air distribution by an active chilled beam. Building and Environment, 2010. 45(9): p. 1932-1940.

34. G. Cao, M.S., J. Kurnitski, M. Ruponen, O. Seppanen, PIV measurement of the attached plane jet velocity field at a high turbulence intensity level in a room. International Journal of Heat and Fluid Flow, 2010. 31(5): p. 897-908.

35. Raffel, M., et al., Particle Image Velocimetry A Practical Guide. Second Edition ed. 2007.

36. Borges, C.M., A.R. Gaspar, and D.A. Quintela. Analysis of the interaction of thermal plumes within office environment using a thermal manikin. in 7th International Thermal Manikin and Modelling Meeting. 2008. University of Coimbra.

37. Rajaratnam, N., Turbulent jets. 1976, Amsterdam, Netherlands: Elsevier Scientific Publishing Company.

38. Verhoff, A., The two-dimensional turbulent wall jet with and without an external stream, P. University, Editor. 1963. 


\section{$\underline{\text { Figure Captions }}$}

Figure 1: (a) Sketch of the climatic chamber - 1 perforated plate, 2 honeycomb, 3 diffuser, 4 dropped ceiling, P1 and P2 acoustic measurement points; (b) positions in the horizontal plane of the room of the heated manikin (HM), and of 16 verticals canes of hot-sphere anemometers and thermocouples; (c) multi-cone diffuser AF842 from ALDES [26] equipped with lobed inserts [2]; (d) swirl diffuser DHV from SCHAKO [14]

Figure 2: (a) Sage Action HSFB generator with the corresponding two injectors; (b-c) Designed injector to increase HSFB flux: (b) photo of the injector, (c) Computer aided design drawing -sectional view

Figure 3 : (a) PIV windows in the vertical half-middle cross section of the room, (b) PIV field in the horizontal cross section $\mathrm{Z}=25 \mathrm{~mm}$ - the dashed line indicates the relative position of the vertical cross section PIV field in the case of the vortex diffuser (VD)-the dimensions are in $\mathrm{mm}$

Figure 4 : Isocolors of velocity magnitude: $(a, b)$ in the half-middle cross section of the room from HFSB-based PIV measurements, for LD and VD respectively; (c) in horizontal jet crosssections for VD, from aerosol-based PIV measurements

Figure 5: (a) Maximum velocity decay of the ceiling jet, (b) Jet width changes

Figure 6: Radial velocity profiles of the cold ceiling jet at different distances from the diffuser outlet

Figure 7: Normalized radial velocity profiles of the cold ceiling jet at different normalized distances from the diffuser outlet - Comparison to data of the literature [37, 38]

Figure 8: Rotation analysis of the jet from the vortex diffuser using horizontal fields of Figure 4c; (a) Considered elementary jet, (b) Local coordinate system and corresponding velocity components, (c) Schematic of yortex diffuser impellers and expected flow trajectory in the horizontal plan, (d) zoom on the elementary jet field, (e) axial evolution of the tangential component $\mathrm{V}$, (f) profiles of the radial component $\mathrm{U}$

Figure 9: Radial velocity profiles of the isothermal ceiling jet at different distances from the diffuser outlet

Figure 10: Maximum velocity decay of the isothermal ceiling jet from vortex diffusercomparison to the literature $[11,12]$

Figure 11: Distributions of PPD, air velocity and temperature in the occupied zone: vortex diffuser VD in cooling mode (a) and lobed multi-cone diffuser LD in cooling mode (b)

Figure 12: (a) Global sound pressure levels (error bar of $\pm 0.7 \mathrm{dBA}$ ) of the diffusers and the ventilation equipment measured at locations P1 (a1) and P2 (a2) of Figure 1 b; (b) Mean sound pressure levels (error bar of $\pm 0.7 \mathrm{dBA}$ ) of the diffusers ; (c) Total pressure loss of the three diffusers (error bar of $\pm 2 \mathrm{~Pa}$ ) 


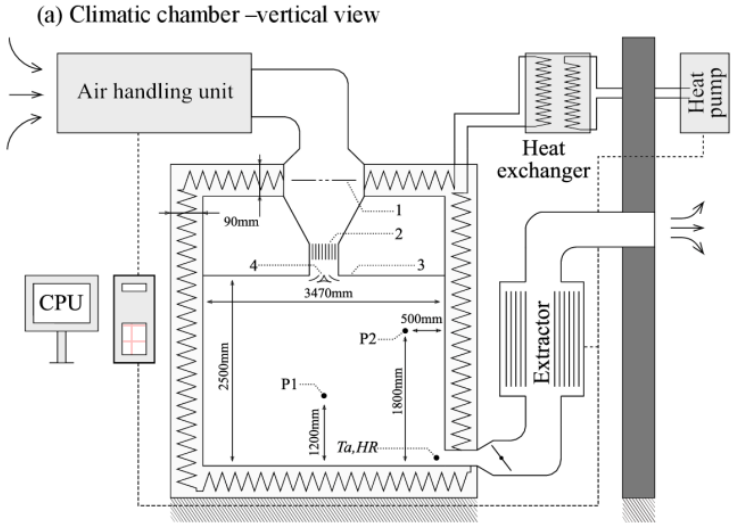

(b) Climatic chamber - horizontal view
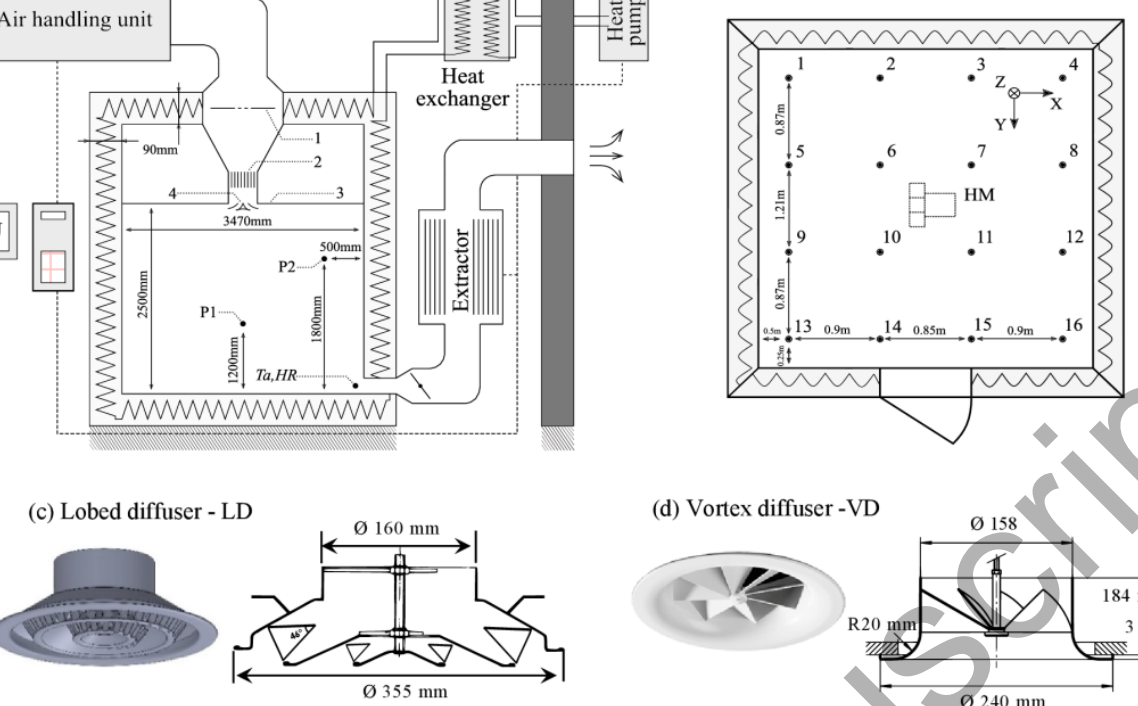

(d) Vortex diffuser -VD

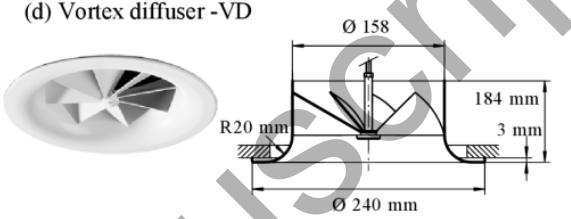


(a)

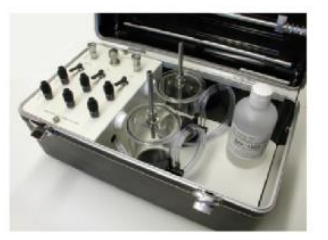

(b)

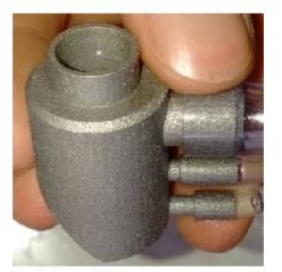

(c)

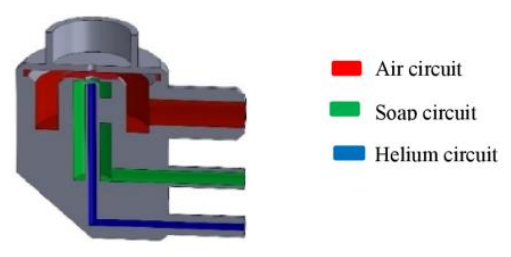

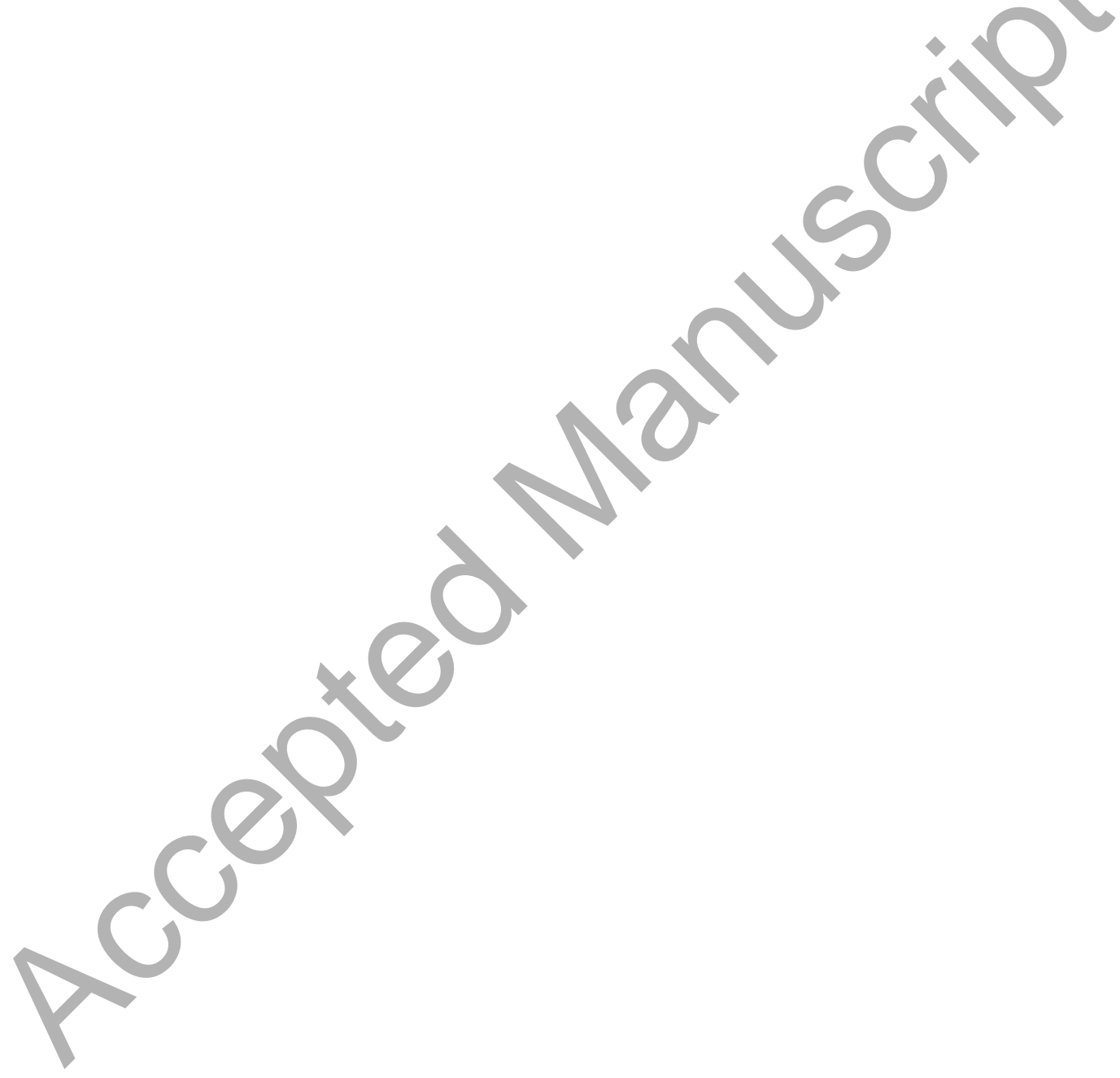




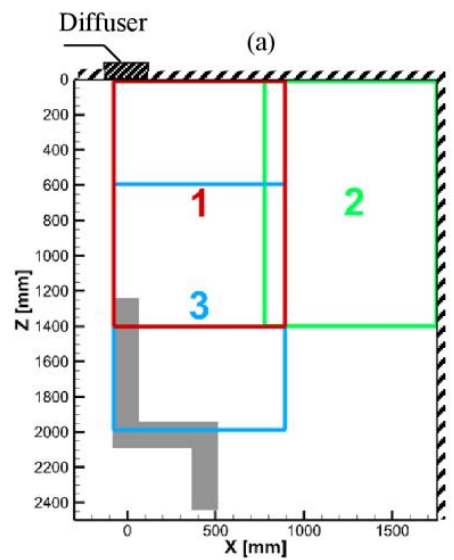

(b)

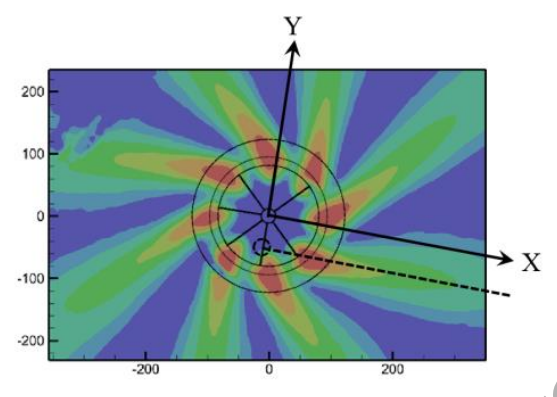

$5^{0}$ 

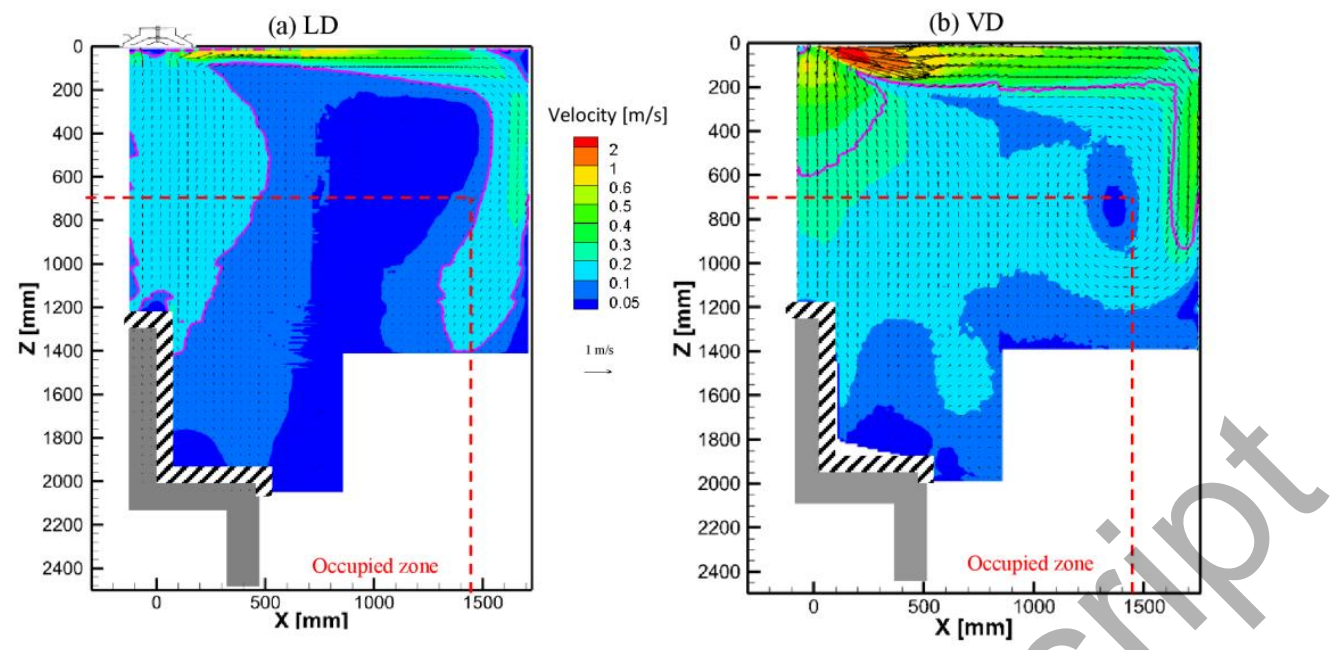

(c) VD

Velocity $[\mathrm{m} / \mathrm{s}]$\begin{tabular}{l|l|llllll} 
& 0.5 & 1 & 2 & & & & \\
\hline
\end{tabular}

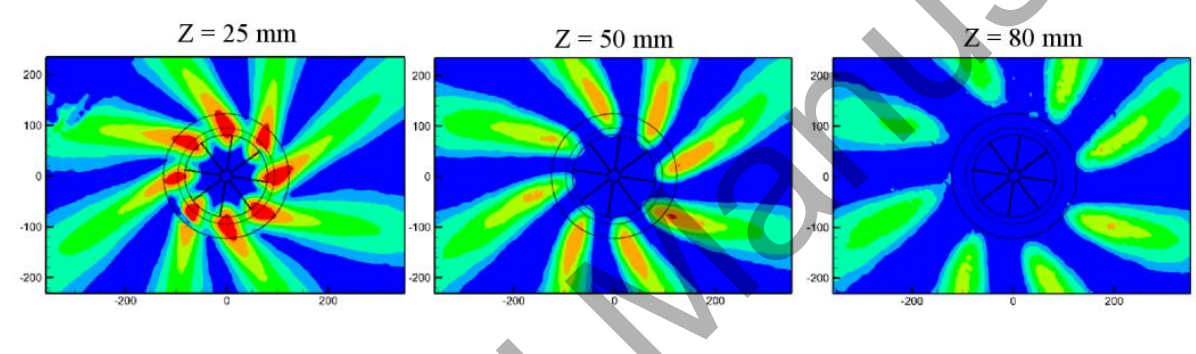



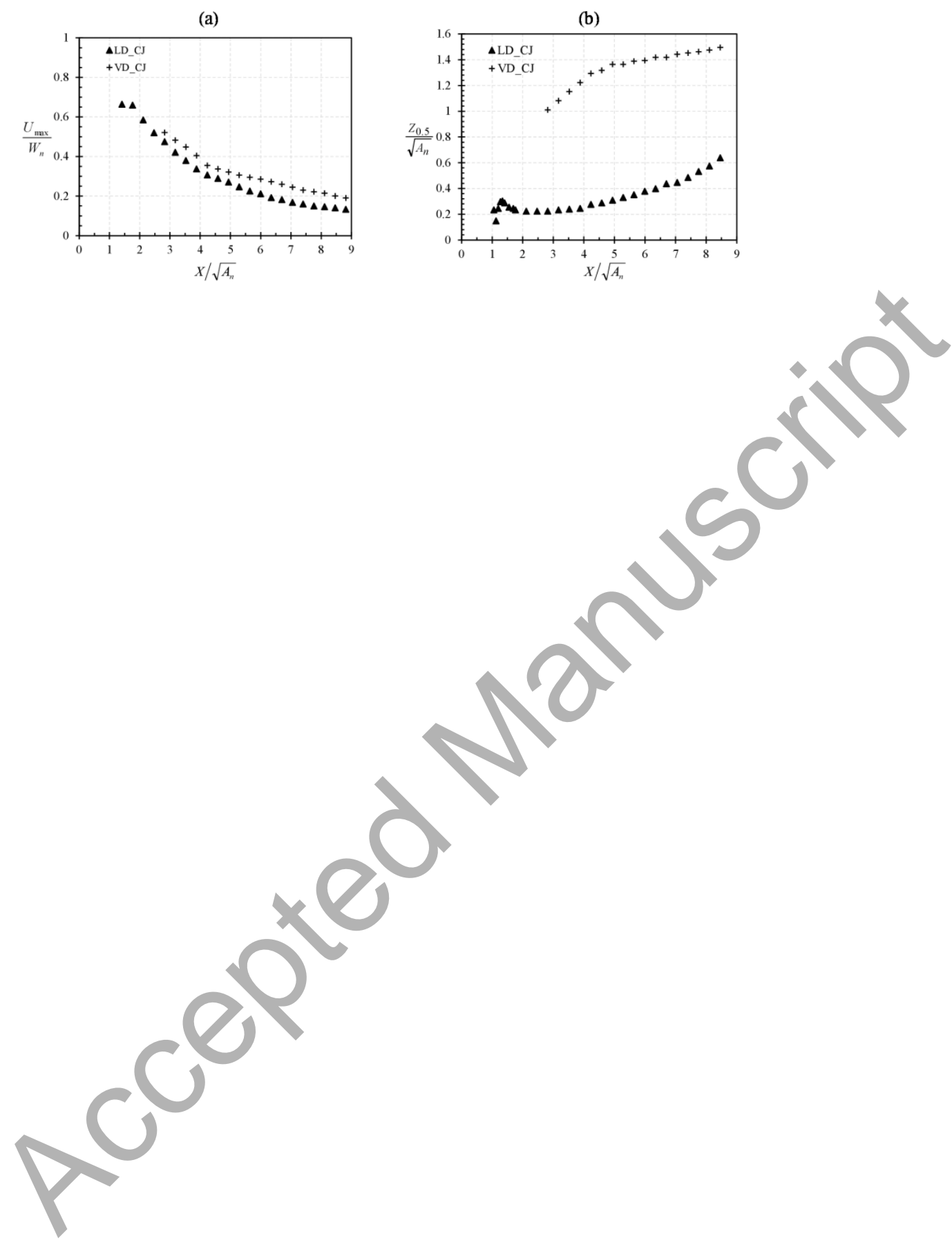

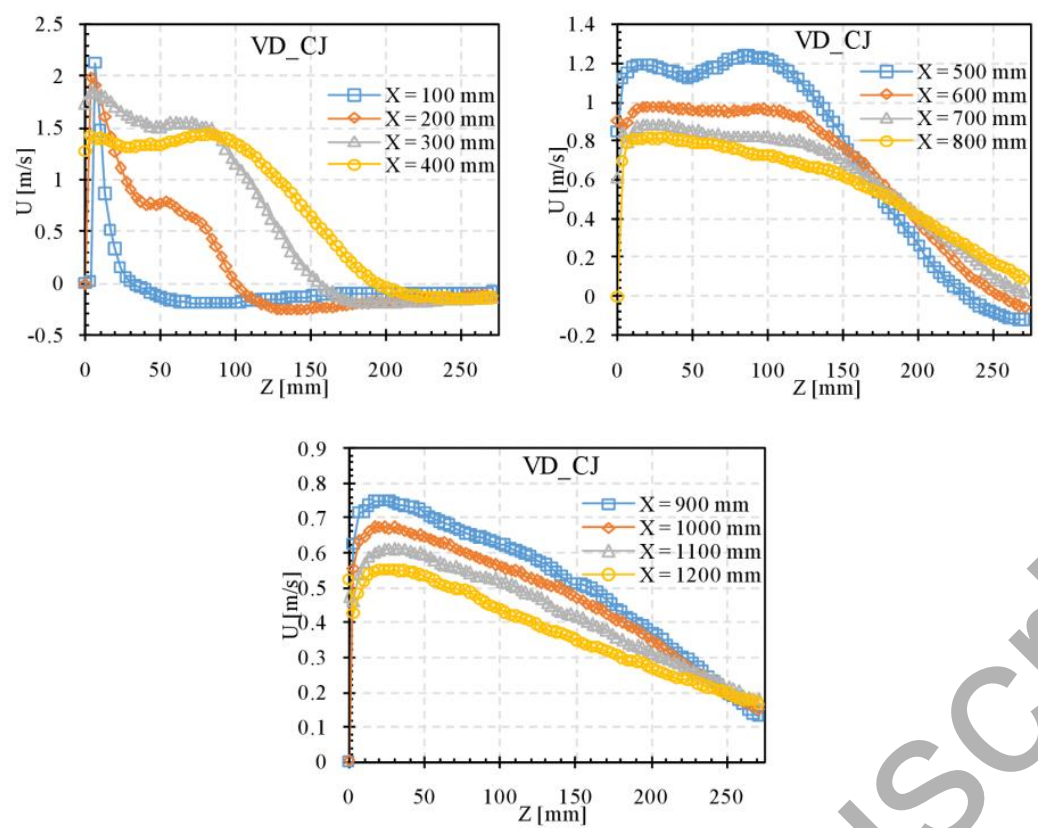

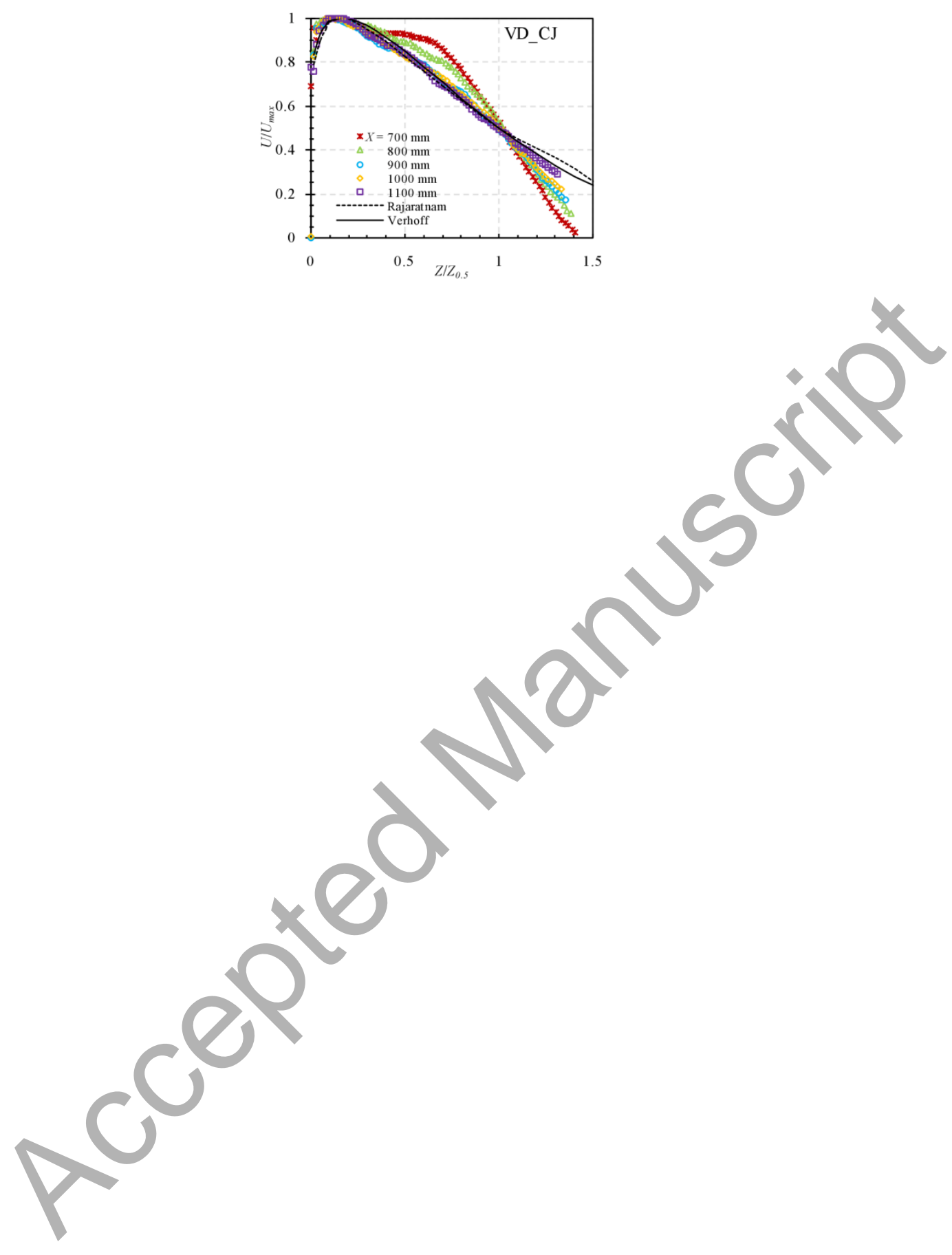


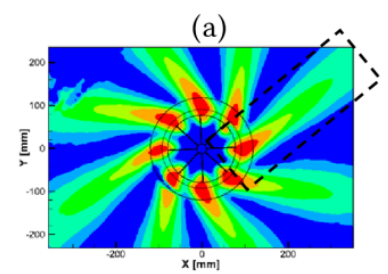

(c)

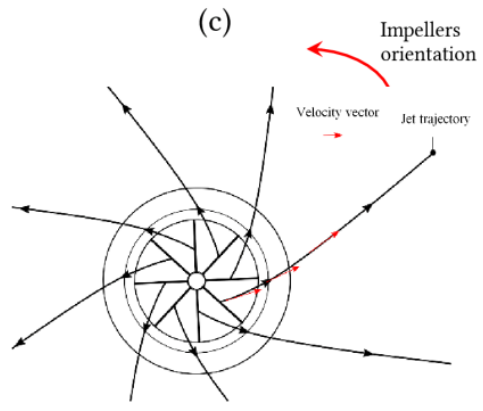

(e)

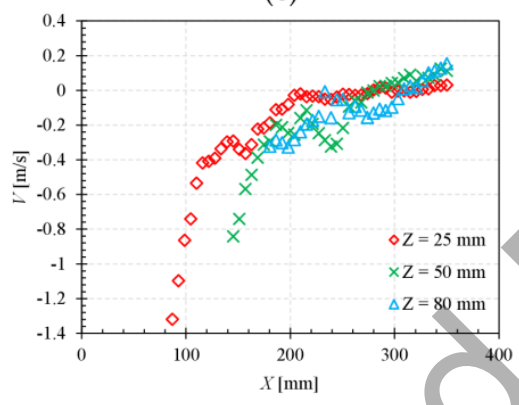

e (b)

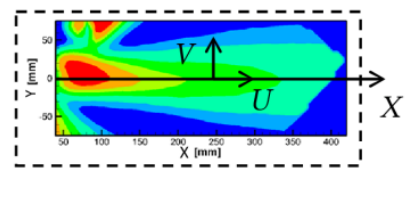

(d)

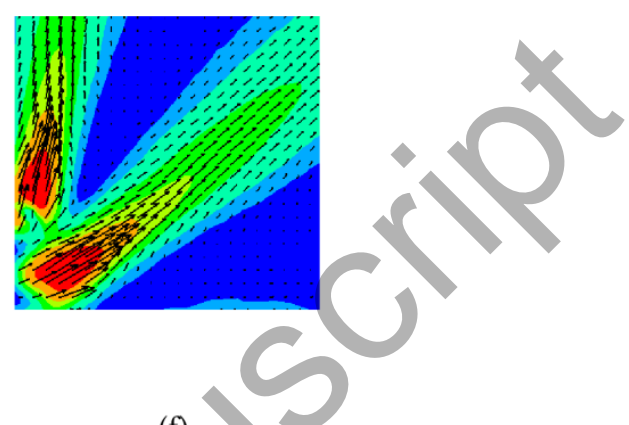

(f)

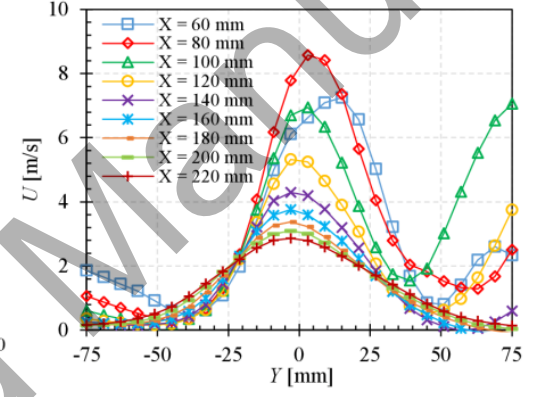



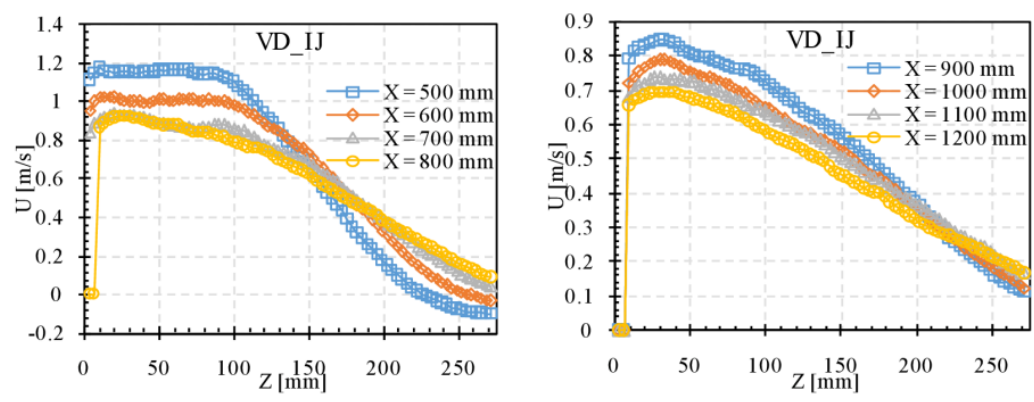


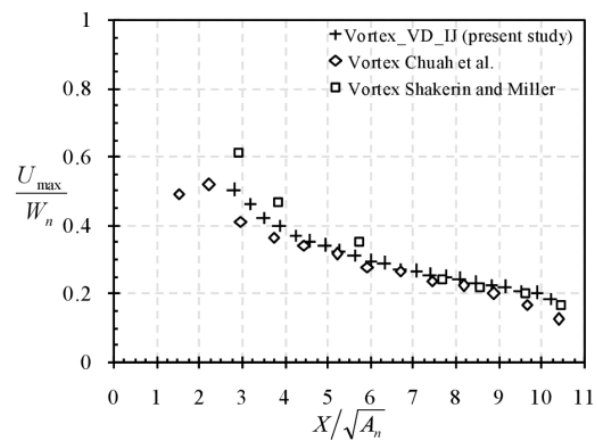


(a) VD_CJ
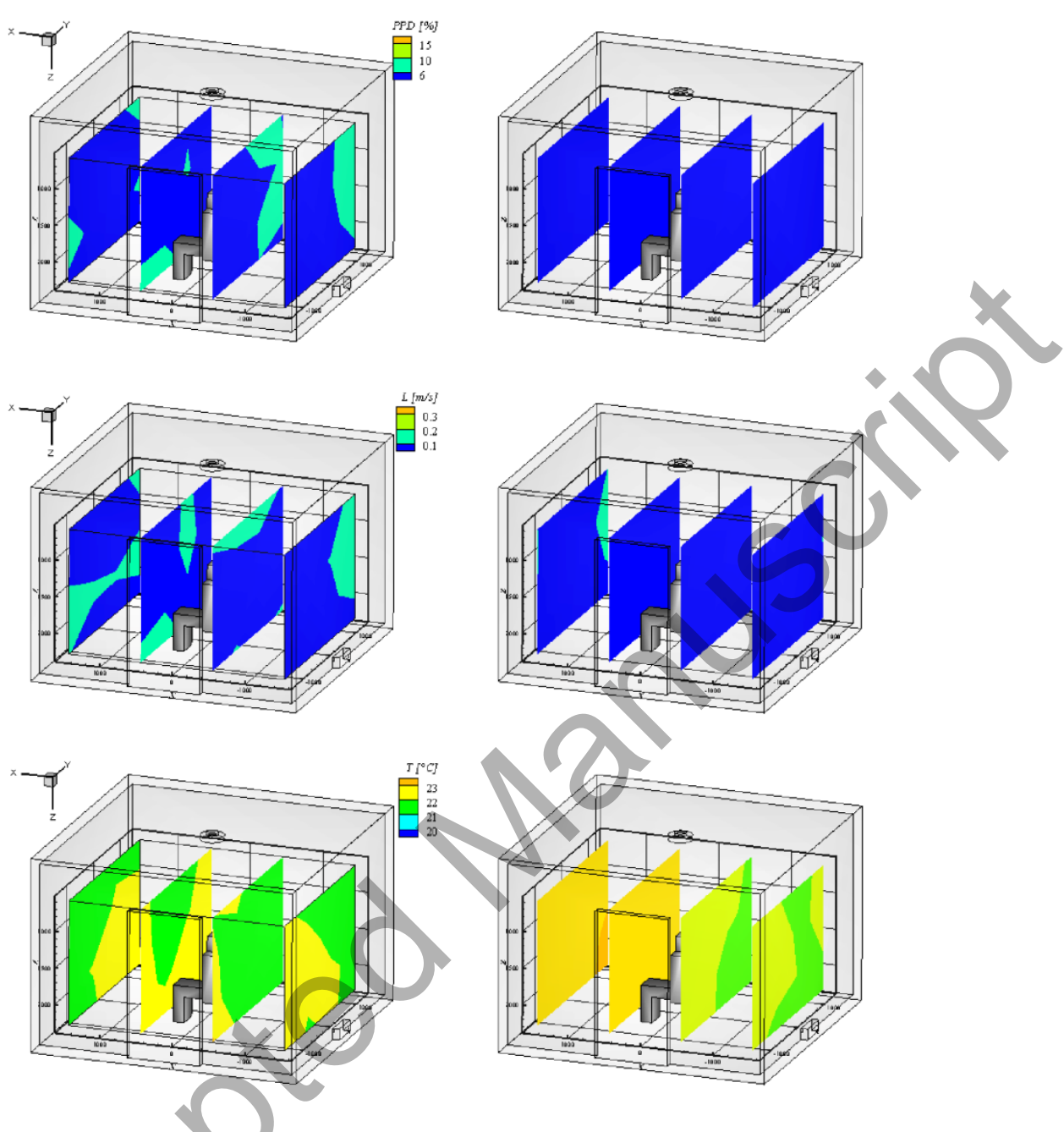
(a1)

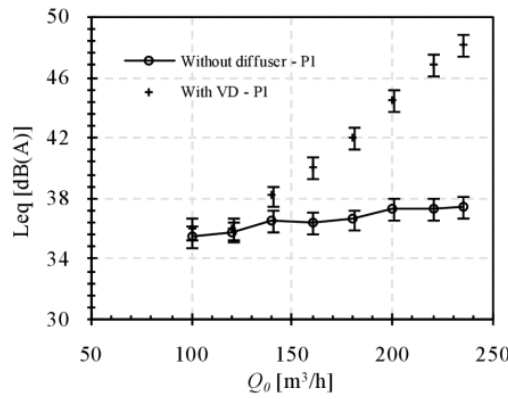

(b)

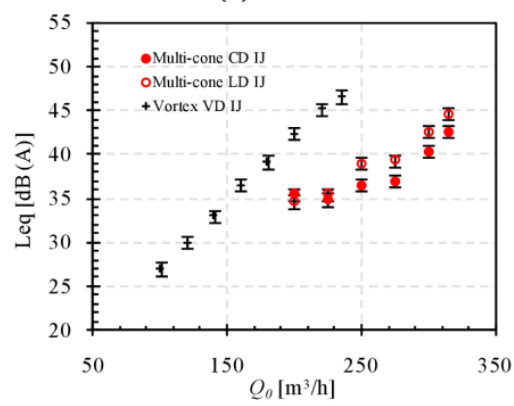

(a2)

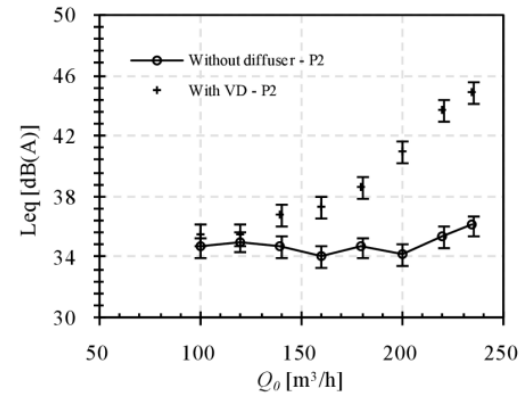

(c)

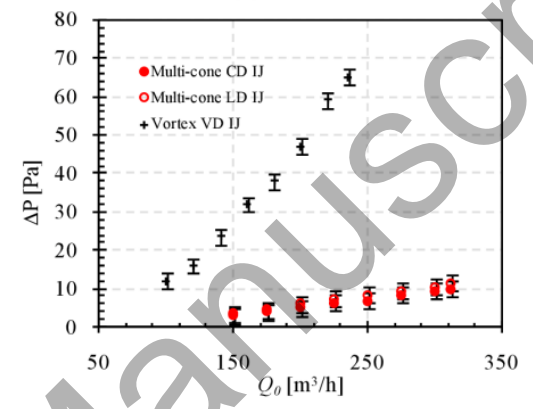

